(2) Open Access Full Text Article

REVIEW

\title{
Association of periodontitis with rheumatoid arthritis and atherosclerosis: Novel paradigms in etiopathogeneses and management?
}

This article was published in the following Dove Press journal:

Open Access Rheumatology: Research and Reviews

28 May 2010

Number of times this article has been viewed

\author{
Mena Soory \\ King's College London Dental \\ Institute, Denmark Hill, London UK
}

Correspondence: Mena Soory

Periodontology, King's College London

Dental Institute, Denmark Hill,

London SE5 9RW, UK

Tel +442032993057

Email mena.soory@kcl.ac.uk

\begin{abstract}
There is increasing documentation of a link between inflammatory periodontal disease affecting the supporting structure of teeth, rheumatoid arthritis, and coronary artery disease. Periodontitis is initiated predominantly by Gram-negative bacteria and progresses as a consequence of the host inflammatory response to periodontal pathogens. Lipopolysaccharide, a cell wall constituent stimulates the production of inflammatory cytokines via the activation of signaling pathways perpetuating inflammatory pathogenesis in a cyclical manner in susceptible individuals; with an element of autoimmune stimulation, not dissimilar to the sequential events seen in RA. Periodontitis, also implicated as a risk factor for cardiovascular disease, promotes mechanisms for atherosclerosis by enhancing an imbalance in systemic inflammatory mediators; more direct mechanisms attributed to microbial products are also implicated in both RA and atherogenesis. Severe periodontal disease characterized by clinical and radiographic parameters has been associated with ischemic stroke risk, significant levels of C-reactive protein and serum amyloid A, amongst others common to both periodontitis and atherosclerosis. Existing data supports the hypothesis that persistent localized infection in periodontitis may influence systemic levels of inflammatory markers and pose a risk for RA and atherosclerosis. A common nucleus of activity in their pathogeneses provides novel paradigms of therapeutic targeting for reciprocal benefit.
\end{abstract}

Keywords: periodontitis, RA, atherosclerosis, periodontal pathogens, cytokines, therapeutic targets

\section{Introduction}

There is growing awareness of the link between periodontal and systemic inflammatory conditions such as (RA) and coronary artery disease based on common etiopathogenic mechanisms. In addition to conventional risk factors for coronary artery disease, emerging risk factors include those associated with chronic inflammatory conditions with an element of autoimmunity in their pattern of progression, such as RA and periodontitis. The latter initiates the loss of supporting structures of the teeth and their eventual loss. These entities have implications in the progression of cardiovascular disease in response to an autoimmune trigger from RA. ${ }^{1-4}$ The risk of a cardiovascular event is significantly increased in RA patients regardless of traditional cardiovascular risk factors, with an emerging paradigm of a common inflammatory pathogenesis. ${ }^{1,5}$ This is also relevant to periodontitis which interestingly has links with increased risk of coronary artery disease independent of conventional risk factors ${ }^{6-8}$ and shows similar cytokine-mediated inflammatory pathology as RA. ${ }^{9-13}$ submit your manuscript $\mid$ www.dovepress.com

Dovepress

10928 
RA, is characterized by chronic synovitis with the resultant damage to joint cartilage and bone which in turn is accompanied by joint pain and reduced mobility affecting $1 \%$ of the adult population. ${ }^{14}$ Chronic periodontitis, initiated by bacterial plaque ${ }^{15}$ is prevalent in a third of the population beyond the age of 50 years and $10 \%-15 \%$ of all adults, ${ }^{16}$ being the main cause of tooth loss in adults. Chronic infection and persistent inflammation are likely to play an important role in the pathogenic progression of atherosclerosis and coronary artery disease. ${ }^{17}$ There is documented evidence of the link between periodontal disease, acute myocardial infarction; ${ }^{7,8}$ and between periodontitis and arthritis. ${ }^{18-20}$

In this context, the concept that RA patients with coronary artery disease will be affected by periodontitis to a greater extent than RA patients without coronary artery disease; and the corollary regarding inflammatory markers being more prevalent in RA patients with coronary artery disease and periodontitis than RA patients with coronary artery disease alone were investigated. ${ }^{21}$ This study showed that the levels of inflammatory mediators were significantly elevated especially in RA patients with coronary artery disease, who were also found to have periodontal disease, emphasizing the relevance of an inflammatory disease burden imposed on the host, which in this case is a central link between the three pathologies. Considering the documented literature in this context, the effective control of significant inflammatory loading from chronic periodontitis as a component of systemic inflammation, has an increasingly probable role in the armamentarium of reducing the risk of morbidity and mortality from systemic diseases. This is subject to the level of inflammation imposed by the periodontal condition, with variations based on disease aggression and its distribution in the mouth. ${ }^{10,22}$ Pathogenic mechanisms common to periodontitis, RA and atherosclerosis, and the potential for therapeutic targeting are discussed.

\section{Oxidative stress induced by cytokines in periodontitis, coronary artery disease and RA}

Periodontal disease has a multifactorial etiopathogenesis, affecting a large proportion of the adult population. Increased levels of C-reactive protein (CRP) and other markers of inflammation are identified. Raised levels of CRP reflect an increased risk of cardiovascular disease. Certain pathological features of atherogenesis are seen in RA, associated with macrophage-activating cytokines tumor necrosis factor- $\alpha$ (TNF- $\alpha$ ), the interleukins IL-1, IL-6, raised levels of the inflammatory marker (CRP) and the enhanced expression of endothelial adhesion molecules including vascular cell adhesion molecule-1 (VCAM-1);23 which is also relevant to chronic periodontitis. There are deeper associations, cardiovascular deaths accounting for up to $50 \%$ mortality in RA patients, reducing life expectancy by $15 \%-20 \%$. A similar trend is reported for systemic lupus erythematosus (SLE) with a significant increase in stroke and myocardial infarction. Subclinical atherosclerosis associated with increased carotid artery intima thickening, indicative of endothelial dysfunction, is seen in SLE and RA, which is related to clinical and radiographic evidence of severe periodontal disease. Atherogenesis associated with inflammatory plaques susceptible to rupture and thrombosis arises from a lipid deposition disorder.

TNF- $\alpha$, high-sensitivity CRP (hs-CRP) and adipokines are relevant markers of inflammation associated with oxidative stress-induced dysregulation of inflammation and lipid metabolism. ${ }^{24}$ The association between obesity and changes in proinflammatory and immunomodulatory cytokines in pregnancy was investigated. ${ }^{25} \mathrm{~A}$ cross-sectional study was carried out using maternal serum in the early second trimester to examine inflammatory biomarkers in relation to maternal body mass index (BMI). Leptin and hs-CRP were shown to be significantly raised with increased BMI. It was concluded that maternal obesity in pregnancy was associated with changes in the expression of cytokines, protein hormones and acute phase proteins in the second trimester with increased leptin and hs-CRP associated with the increasing BMI category. The effect of a standardized oral lipid load on parameters of inflammation was investigated in a large sample of healthy adults. ${ }^{26}$ All patients underwent a measurement of BMI, blood glucose, blood pressure, total cholesterol, both low-density lipoprotein (LDL) and high-density lipoprotein (HDL) cholesterol, triglycerides, soluble intercellular adhesion molecule-1 (sICAM-1), IL-6, CRP, soluble E-selectin (sE-selectin) and TNF- $\alpha$. Oral lipid loading produced a complex and massive systemic inflammatory response. There were demonstrable increases in hs-CRP, sE-selectin, IL-6, and TNF- $\alpha$ even before a significant rise in triglyceride occurred. These findings could be extrapolated to metabolic diseases with dysregulation of lipid metabolism, also seen in periodontal patients with coexisting inflammatory diseases and therapeutic targets to combat oxidative stress. ${ }^{27-30}$

Immuno-inflammatory diseases are fuelled by cytokines and regulated by cytokine inhibitors. In order to determine the periodontal disease-specific characteristics in periodontal subjects, relative to patients with more generalized chronic inflammation, patients with juvenile idiopathic arthritis and 
RA were included to investigate whether peripheral blood monocyte gene expression of clinically important pro- and anti-inflammatory cytokines corresponded with plasma levels. ${ }^{31}$ This investigation demonstrated only limited differences in the expression of various cytokine and cytokine inhibitor genes in aggressive periodontitis and chronic arthritis compared with controls. There were some similarities among disease groups although no direct correlation between genetic expression and serum parameters. High levels of heat shock proteins (hsp) of $70 \mathrm{kDa}$ associated with periodontal pathogens and periodontal disease progression, have been isolated in synovial tissue of RA patients. When hsp 70 expression is induced via stressors, the proinflammatory cytokines TNF- $\alpha$, IL-1, and IL-6 have been identified in the RA synovium. ${ }^{32}$

Gender-specific differences in systemic cytokine levels were compared in rats with or without ligature-induced periodontitis. ${ }^{33}$ Experimental periodontal disease was induced in Sprague-Dawley rats by placing ligatures around a molar tooth with sham operated controls. Cytokine levels were assayed by ELISA. Female rats with ligatures had greater yet significantly different alveolar bone loss than males with ligatures. However they had higher serum concentrations of IL-6, TNF- $\alpha$, and CRP. Those females also had higher levels of IL-6, TNF- $\alpha$, and vascular endothelial growth factor (VEGF) in the uterine horn compared with female controls $(P<0.05)$. Male rats with ligatures had lower serum CRP and higher levels of IL- 6 and TNF- $\alpha$ compared with male controls. This study suggests that females with periodontal disease have a greater risk for inflammation-based systemic diseases than males, if these results could be extrapolated to humans.

Chronic periodontitis, RA, and coronary artery disease have a common nucleus of activity which accounts for the coexistence of these diseases, common risk markers ${ }^{34}$ and potential therapeutic strategies.

\section{The role of periodontal pathogens in chronic periodontitis, $R A$, and coronary artery disease Association of periodontal pathogens with RA}

RA leads to joint destruction and consequent disability. There is progressive documentation of a link between RA and periodontal disease. Porphyromonas gingivalis $(\mathrm{Pg})$ is a significant periodontal pathogen; it is the only bacterium known to possess a peptidyl arginine deiminase (PAD) which generates a citrullinated peptide by post-translational modification (citrullination) of protein bound arginine; the citrullinated peptide and anti-cyclic citrullinated peptide (anti-CCP) autoantibody are capable of breaking down selftolerance and lead to the development of autoimmune RA. ${ }^{35}$ There is a significant rise in antibody titer to $P g$ in patients with RA and there is a significant correlation with anti-CCP antibody isotypes specific to RA. Deiminated forms of the alpha- and betachains of fibrin are major synovial targets of RA-specific anti-CCP antibodies. It has also been shown that PAD produced by $P g$ is able to deiminate arginine in fibrin found in the periodontal lesion. Citrullination of human leukocyte antigen (HLA) binding peptide causes a 100-fold increase in peptide - major histocompatibility complex (MHC) affinity and leads to $\mathrm{CD}^{+} \mathrm{T}$ cell activation in the HLA DRB1 040 allele of transgenic mice. These findings are suggestive of a crucial role for $P g$ in the pathogenesis of RA associated with periodontitis. Constant production of PAD by $P g$ could result in citrullination of fibrin in the synovium; antigens presented in association with $\mathrm{MHC}$ molecules by antigen presenting cells leads to the production of anti-CCP antibody. These antibodies form immune complexes with citrullinated proteins, which can bind to inflammatory cells via their Fc receptors, leading to activation of the complement cascade. The resultant release of inflammatory mediators leads to joint destruction and RA. Uncontrolled periodontal disease could play a role in the development of RA via peptide citrullination involved in loss of self-tolerance and autoimmune destruction of synovial tissue.

Osteoimmunology involving the interaction of the immune system with skeletal elements leads to the formation of osseous lesions. To investigate the contribution of an acquired immune response in the formation of osteolytic lesion, the periodontal pathogen $\mathrm{Pg}$ was injected adjacent to calvarial bone with or without prior immunization against $P g \cdot{ }^{36}$ Activation of the acquired immune response elevated osteoclastogenesis and decreased bone formation associated with an increase in nuclear translocation of the transcription factor FOXO1 (forkhead box O1) in vivo, enhanced apoptosis of bone lining cells caspase- 3 positive cells and a decrease in bone lining cell density. These activities were induced when a combination of cytokines such as IL- $1 \beta$, TNF- $\alpha$, and IFN- $\gamma$ were tested. It is significant that FOXO1 knockout by a small interfering RNA significantly reduced cytokine-stimulated apoptosis, mRNA levels of proapoptotic genes, cytokines, and caspases-3, -8, and -9 . These results indicate that acquired immunity could trigger apoptosis, osteoclastogenesis, and bone resorption. This could occur by stimulation of bone lining cell apoptosis via FOXO1 activation. This study 
demonstrates commonalities in the pathogenesis of chronic periodontal disease and RA where osteogenesis and bone destruction occur hand in hand in response to activation of an acquired immune response.

Periodontal disease has been implicated as a risk factor for RA. Raised antibody titers to $P g$ in patients with RA are associated with disease-specific autoimmunity. Antibody titers to $P g$ were characterized in patients with periodontitis, RA and healthy controls for correlation with disease autoantibodies. ${ }^{37}$ $P g$ antibody titer was correlated with CRP, antibody to cyclic citrullinated peptide (anti-CCP) and rheumatoid factor (RF). Antibody titer to $P g$ was highest in periodontitis, intermediate in RA and lowest in controls $(P<0.0003)$, showing a greater association with periodontitis and RA than controls. Correlations between $P g$ titers, concentrations of CRP and autoantibody related to RA is suggestive of the role of $P g$ in the etiopathogenesis of periodontal disease, being a risk factor for RA and its progression.

The impact of controlling periodontal infection, by reducing the concentration of pathogens, with thorough initial phase debridement of periodontal pockets in reducing the severity of active RA has been reported. ${ }^{38}$ There is evidence that autoantibodies formed against oral anaerobes have important implications in the etiopathogenesis of RA. ${ }^{39}$ The pathogenesis of RA resembles that of periodontitis, both conditions presenting with a high frequency of HLA-DR4 tissue antigens and there is increasing documentation of the coexistence of the two conditions. ${ }^{18}$ Antibodies to Gram-negative, anaerobic periodontal pathogens such as Porphyromonas gingivalis, Prevotella intermedia, P. melaninogenica, and Tannerella forsythensis have been detected in the serum and synovial fluid of RA patients. These pathogens have been identified in the synovial fluid of RA patients, with higher levels of bacterial DNA in RA patients than in controls. ${ }^{40}$ Rheumatoid autoantibodies target epitopes created by deimination of arginine residues in autoantigenic proteins such as profilaggrin/ filaggrin, fibrinogen/fibrin, keratin and vimentin. Arginine is dominant amongst the amino acids in its autoantigenicity amongst proteins. Expression of a peptidyl deiminase in $P g$ and arginine specific proteinases in T. forsythensis and Treponema denticola have been reported. ${ }^{41}$ These findings are suggestive of an important role for oral pathogens in the perpetuation of synovial inflammation in response to the antigenic stimulus of their bacterial DNA.

The role of the periodontal pathogen $P$. gingivalis in the pathogenesis of RA was investigated in cell cycle progression and the apoptosis of human articular chondrocytes. ${ }^{42}$ Monolayer cultures of human chondrocytes were challenged with
P. gingivalis and their cell cycle progression was analyzed using scanning electron microscopy, immunofluorescence, flow cytometry, Western blot analysis and labeling techniques. Results showed that $P$. gingivalis adhered to and infected primary human chondrocytes demonstrated by its intracellular localization. Progression of the cell cycle was also affected. Apoptotic signaling cascades were evidenced by the TUNEL (terminal transferase dUTP nick end labeling) assay showing DNA degradation and an up-regulation of caspase-3 protein expression in infected chondrocytes. This study shows that $P$. gingivalis could contribute to tissue damage seen in the progression of RA by infecting chondrocytes. Some T-cell receptor genes Vbeta genes are more frequently identified in RA patients than in controls. ${ }^{43}$ It is relevant that the periodontal pathogen $P g$ specifically stimulates the expression of Vbeta 8 and Vbeta 17 genes in $\mathrm{CD}^{+}{ }^{+} \mathrm{T}$ cells, ${ }^{44}$ demonstrating a connection between the immunopathology of periodontal disease and RA.

\section{Association of periodontal pathogens with atherosclerosis}

The pathogen-associated molecular pattern receptors, known as toll-like receptors (TLR), play an important role in immune signaling in response to microbial infection and chronic inflammatory diseases such as atherosclerosis. Deficient TLR signaling reduces inflammatory responses associated with atherosclerosis in hyperlipidemic mice. Specific intervention strategy utilizing immunization in the prevention of pathogenaccelerated atherosclerosis has been shown to be effective. ${ }^{45}$

The periodontal pathogen $P g$ has been implicated in the progression of atherosclerosis. It has been demonstrated to reside in the walls of atherosclerotic vessels and seroepidemiological studies show an association between $P g$-specific IgG antibodies and atherosclerosis. Signaling pathways utilized by $P g$ depends on the cell type. Oral inflammatory bone loss is associated with stimulation of TLR2 by $P g$ which also expedites atherosclerosis in hyperlipidemic mice demonstrating increased expression of TLR2 and TLR4 in atherosclerotic lesions. Immune and inflammatory mechanisms of atherosclerosis are well documented ${ }^{46}$ and their implications in periodontal pathology. ${ }^{47}$

Atherogenic forms of dyslipidemia may be seen in subjects with RA with increased cardiovascular risk. In addition to an alteration in plasma lipids it is likely that this population demonstrates smaller LDL molecules and an altered subclass distribution. ${ }^{48}$ Elevated levels of plasma triglycerides and decreased levels of HDL-cholesterol were seen in RA patients when compared with healthy controls. Total- and LDL-cholesterol 
levels were similar. A third of RA patients showed a complete 'atherogenic-lipoprotein phenotype,' demonstrating the concomitant presence of elevated triglycerides, decreased HDL-cholesterol and raised levels of small dense LDL. The prevalence of small dense LDL in drug-naïve patients with early RA needs further investigation with regard to its influence on the atherogenic process and clinical endpoints. Further associations between dyslipidemic atherogenesis and RA, also relevant to chronic periodontitis, are considered under clinical associations.

\section{Clinical correlations between periodontitis, rheumatoid arthritis and cardiovascular disease Clinical correlations between chronic periodontitis and RA}

The association between circulating proinflammatory mediators TNF- $\alpha$, IL- $1 \beta$, prostaglandin $\mathrm{E}_{2}$, serotonin, rheumatoid factor and periodontitis in patients with RA was investigated. ${ }^{49}$ Periodontal parameters such as clinical attachment level (CAL) to bone, probing depth (PD) and gingival bleeding on probing (BOP), assessment of furcation invasions and increased tooth mobility were made in addition to the number of teeth present in 30 subjects. All subjects were nonsmokers. Measurement of the parameters for gingivitis and periodontal disease showed a high degree of correlation with plasma levels of TNF- $\alpha$ in patients with RA when compared with healthy controls.

Documentation demonstrating a higher prevalence of periodontal disease among individuals with RA is limited and sometimes inconsistent. Questionnaires were used to assess potential risk factors for periodontal disease such as smoking, education, alcohol consumption, BMI and coexisting diseases associated with RA and periodontal disease. Periodontal parameters of attachment loss, plaque and bleeding indices were obtained.$^{50}$ It is relevant that in a stepwise logistic regression including the above parameters (RA status, age, gender, education, smoking, alcohol consumption and BMI), only RA status and age were significant predictors of periodontal disease. Subjects with RA were shown to have significantly increased odds of periodontal disease when compared with controls (95\% confidence interval [CI]: 2.93 to 22.09). After adjustment for plaque and bleeding indices (which accounted for $13.4 \%$ of the association between RA and periodontal diseases), the strength of the association remained significant, although attenuated. It was concluded that there was significantly greater periodontal attachment loss in subjects with RA, compared with controls and bacterial plaque was only partly responsible for this association, implying that an overexuberant inflammatory response to optimal amounts of plaque could account for similarities in disease pathogeneses in the two conditions.

Potential mechanisms relevant to the association between periodontal and synovial inflammation include commonalities in cellular, molecular and pathological features. ${ }^{51}$ Particularly the progression of destructive changes in associated tissues shows similarities. Anticitrullinated protein antibodies (ACPA) are highly specific antibodies for RA. They are specific risk markers for RA which are demonstrable years before onset of the disease. There is evidence to suggest that immune tolerance could be disrupted by the periodontal pathogen $P$. gingivalis by enhancing autoimmune responses to citrullinated antigens. This sequence of events could trigger the initiation and progression of RA in genetically susceptible individuals. Improved treatment strategies could modify the progression of diseases with an inflammatory pathogenesis, to the advantage of the patient. ${ }^{52}$

A greater prevalence of periodontal disease and tooth loss has been reported amongst subjects with RA. Autoimmune inflammatory responses that occur in RA may be sustained as a result of periodontal inflammation which could represent a risk factor for RA, altered by treatment. ${ }^{53}$ Common genetic and environmental factors could predispose to both independently. Both RA and periodontal disease have a wide prevalence amongst inflammatory diseases with several common mechanisms in their pathogenesis associated with tissue destruction. Some of the common clinical and biological links between the two disease entities have been reviewed recently. ${ }^{54}$ A relatively limited number of studies in this area make it difficult to provide conclusive evidence.

Juvenile idiopathic arthritis (JIA) is a severe disease of childhood comprising a diverse group of clinical entities associated with abnormal function of the immune system which could result in abnormalities in growth and development, affecting the temporomandibular joint and mandible. ${ }^{55}$ An increased prevalence in caries and periodontal disease in JIA patients may be partly attributed to unfavorable dietary practices, difficulty in maintaining good plaque control and side effects from long-term medication; and in the case of periodontal disease progression an association with JIA is based on a dysregulated inflammatory response relevant to its pathogenesis. The periodontal condition in children and adolescents with JIA was compared with age-matched healthy controls. ${ }^{56}$ Forty-one JIA patients were compared with 41 controls. The frequency of sites with plaque, 
calculus, bleeding on probing and probing depth of $2 \mathrm{~mm}$ was significantly greater in JIA patients. There were no sites with attachment loss or reduced marginal bone levels. It was concluded that the results were partly explained by joint pain, making it difficult to perform good oral hygiene procedures, general disease activity and medication. The association of the HLA in patients with juvenile idiopathic arthritis, generalized aggressive periodontitis and chronic periodontitis was evaluated in comparison to healthy controls. ${ }^{57}$ Females suffering from JIA and chronic periodontitis demonstrated HLA-DRB3 to a greater extent than controls, with a greater likelihood of attachment loss in JIA cases with this configuration. It is possible that JIA and chronic periodontitis among females pose a common risk factor in HLA-DRB3.

\section{Clinical correlations between RA and coronary artery disease}

The association between RA, coronary artery disease, periodontal disease and systemic inflammatory markers has been evaluated recently. ${ }^{21,58} \mathrm{An}$ accelerated vascular risk in RA leads to increased prevalence of coronary artery disease with associated risk of increased morbidity and early mortality. A total of 100 active RA patients of whom 50 showed established coronary artery disease and the rest with no coronary artery disease, were assessed for periodontal disease. Clinical, cardiac, dental, laboratory and radiological evaluation were performed in all patients. These findings demonstrated an association between RA, coronary artery disease and periodontal disease. Patients with RA and coronary artery disease had significantly more periodontitis than those with RA alone $(P<0.001)$. There were raised levels of the inflammatory markers hs-CRP, erythrocyte sedimentation rate (ESR), white blood cell (WBC), fibrinogen and TNF- $\alpha$ in all patients but significantly higher in RA patients with coexisting coronary artery disease and periodontal disease; correlating with the degree of inflammatory burden likely to be present in the latter case. Levels of HDL-cholesterol were significantly lower in RA patients with coexisting coronary artery disease than in those with RA alone. These findings highlight the relevance of an inflammatory burden which is central to the association between RA, coronary artery disease, periodontal disease.

Mechanisms involved in accelerated atherosclerosis seen in chronic inflammatory diseases warrant further investigation. Preclinical atherosclerosis in RA patients was compared with diabetes mellitus as an established atherosclerotic model. A group of 84 patients with RA and no cardiovascular disease were examined against age and sex matched healthy controls for endothelial function, atheromatous plaques, carotid intima-media thickness and arterial stiffness; these comparisons were also made between 48 diabetes patients and 48 RA patients. ${ }^{59}$ Arterial stiffening was associated with duration of RA, while there were correlations between disease activity and carotid plaque vulnerability. Markers of preclinical atherosclerosis were significantly worse in RA in comparison with controls, whereas these findings did not differ in the diabetes group despite a significant cardiovascular risk profile in diabetics. RA was independently associated with endothelial dysfunction while both RA and diabetes showed independent correlations with increased intima-media thickness. There appears to be equal prevalence and severity of preclinical atherosclerosis in RA and diabetes of a similar duration, with differential impact of systemic inflammation and conventional risk factors.

Adipose tissue functions as an active endocrine organ, producing adipokines. Adiponectin and leptin concentrations were evaluated in $80 \mathrm{RA}$ patients in relation to disease activity and duration. ${ }^{60}$ There were significant negative correlations between levels of adipokines and lipid profile components such as adiponectin and HDL-cholesterol; and positive correlations between leptin and total cholesterol as well as LDL-cholesterol. A negative correlation between adiponectin levels and the number of swollen, tender joints; and a positive correlation between disease activity and leptin levels have been demonstrated. These findings confirm the role of adipokines in the inflammatory process and atherosclerosis demonstrating the anti-inflammatory protective role of adiponectin and the proinflammatory, proatherogenic role of leptin.

Arterial calcification in patients with RA has been evaluated in view of the fact that subjects with arthritis are prone to premature atherosclerosis; ${ }^{61}$ however, the prevalence and degree of calcification in different vascular beds and their interrelationship requires clarification. The distribution and extent of arterial calcification was determined in 85 patients with RA and an equal number of age- and sex-matched controls. ${ }^{62}$ Arterial calcification was determined by a calcium score using computer tomography in the thoracic aorta, coronary and carotid arteries. The calcium score was significantly higher in RA patients with a greater risk of developing calcification in the aorta, followed by carotid, coronary and arteries overall, when compared with controls. Diffuse arterial calcification was detected in $90 \%$ of RA patients over 60 years of age, especially in the thoracic aorta, compared with $55 \%$ of controls who showed arterial calcification clustered in the coronary arteries. When arterial calcification was present in RA patients, they were older with higher levels of urea 
and CRP than those with no arterial calcification. Patients with RA had an earlier onset of arterial calcification, which was more diffuse over multiple sites, with a preferential distribution in the thoracic aorta than in the coronary artery compared with controls.

There has been recent documentation of the large spectrum of disease pathology affecting patients with RA including rheumatoid vasculitis to atherosclerotic lesions. The relevance of rheumatoid vascular disease and atherosclerosis relevant to cardiovascular morbidity and global mortality has received attention in recent literature. ${ }^{63}$ The management of cardiovascular risk in RA patients has become increasingly important in view of the consequences of its inflammatory pathogenesis leading to endothelial dysfunction and atherosclerotic risk.

\section{Clinical correlations between coronary artery disease and chronic periodontitis}

There are multifactorial diseases which could present primarily with atherosclerotic lesions. Considering global morbidity and mortality from cardiovascular diseases, it is relevant that inflammatory periodontitis affecting supporting structures of the teeth is a risk factor for cardiovascular disease and is also prevalent globally. The pathogenesis of atheroma formation in periodontal patients is a progression of a host-mediated inflammatory response to periodontal pathogens and their components mediated by the release of matrix metalloproteinases and alteration in lipoprotein metabolism. It follows that treatment of periodontal disease along with adoption of preventive measures against recognized risk factors such as smoking, hypertension, dyslipidemia, diabetes and obesity could reduce morbidity and mortality of cardiovascular diseases. ${ }^{64}$ Recent documentation supports these concepts. ${ }^{65}$ Further large, controlled clinical trials are required to reinforce these findings.

The association between chronic periodontitis and cardiovascular risk markers has been investigated. ${ }^{66}$ The levels of triglycerides were significantly elevated in periodontitis patients, while HDL-cholesterol levels were significantly lower in comparison with controls. Total cholesterol, LDLcholesterol and lipid peroxide levels were the same in both groups, while levels of IL-6, IL8, antibodies against oxidized LDL, leukocyte and neutrophil counts were significantly higher in periodontitis patients, thus reinforcing documented associations.

As hyperlipidemia is a major risk factor for cardiovascular disease, a possible association between periodontitis and hyperlipidemia was investigated. ${ }^{67}$ Fifty-one hyperlipidemic and 47 normolipidemic subjects were investigated for plasma triglyceride, both HDL- and LDL-cholesterol, total cholesterol and periodontal parameters, including sites that bled on probing. The mean values for periodontal parameters such as plaque index, probing depths, clinical attachment levels and bleeding on probing showed significant and positive correlations in hyperlipidemic subjects compared with controls. Plasma triglyceride, total cholesterol, and LDL-cholesterol levels demonstrated a significant positive association with periodontal parameters, while HDL-cholesterol showed a significant negative correlation with clinical attachment levels of tooth support. Plasma triglyceride levels showed significant association with periodontitis and bleeding on probing. While further studies are required to establish the effect of hyperlipidemia on periodontitis, these results suggest that hyperlipidemic subjects showed worse disease parameters for periodontitis than normolipidemic subjects.

The pathological links between periodontitis and coronary artery disease pose a logical argument for a cause and effect relationship, although they remain controversial. Investigation of levels of total cholesterol, triglyceride, glucose and probing pocket depths in 71 patients suggested that the percentage of periodontal pockets deeper than $4 \mathrm{~mm}$ increased with raised levels of total blood cholesterol; ${ }^{68}$ although these trends were not significant. Further work with larger numbers may be required in order to establish conclusive links between hypertriglyceridemia, hypercholesterolemia, and periodontitis.

\section{Therapeutic targets and their implications Blockade of TNF- $\alpha$}

Several inflammatory cytokines, particularly TNF- $\alpha$, IL-1, IL-6, and IL-17 are involved in sequential differentiation, maturation and activation of osteoblasts and osteoclasts, thereby influencing a critical balance between bone formation and bone resorption. ${ }^{69}$ Anti-TNF antibodies such as infliximab, adalimumab and a TNF receptor $\mathrm{Fc}$-fusion protein etanercept have had a successful outcome in the treatment of RA, psoriatic arthritis, ankylosing spondylitis and chronic inflammatory bowel diseases. TNF blockade is effective in attenuating the progression of inflammatory joint destruction and also the clinical symptoms of inflammation. ${ }^{70-71}$ It also has applications in suppressing systemic osteoporosis..$^{72}$ Treatment may not always be effective and agents could gradually lose their effect. High-throughput leukocytapheresis has been found to be effective over a period of time in patients with a reduced response to infliximab. ${ }^{73}$

In view of the benefits of TNF- $\alpha$ blockade in treating RA, its efficacy in controlling coexisting periodontal disease was 
investigated, in the context of similarities between the two disease entities with regard to TNF- $\alpha$-mediated bone loss in their pathogeneses..$^{74}$ Infliximab tended to aggravate gingival inflammation. It is possible that the persistence of plaque could have contributed to gingival irritation and inflammation associated with chronically enlarged gingivae, although infliximab prevented attachment loss and progressive bone loss in this study, independent of superficial inflammation of the gingivae. Methotrexate had no impact on periodontal status. In a further study, ${ }^{75}$ it was demonstrated that when the mean plaque score was similar amongst two study groups of RA patients with or without infliximab infusions and a third group of healthy controls, gingival inflammation was greater in the RA group that did not receive infliximab infusions; the lowest levels of TNF- $\alpha$ in crevicular fluid were detected in those receiving infliximab. Attachment loss was decreased after treatment with infliximab in periodontal patients with RA. It was concluded that TNF- $\alpha$ blockade could be beneficial in the treatment of periodontitis as an adjunct to root surface debridement. This concept is emphasized in a study utilizing 40 patients with moderately severe RA and severe periodontal disease randomly assigned to receive thorough nonsurgical periodontal therapy comprising plaque control, scaling and root surface debridement. ${ }^{76}$ All patients received disease-modifying antirheumatic drugs. There were significant decreases in RA disease activity scores and serum TNF- $\alpha$ in patients receiving initial phase nonsurgical periodontal treatment, with a concomitant improvement in periodontal disease parameters and bone loss. There was no significant change in those not receiving periodontal care, regardless of the medication used. This underscores the importance of adjunctive periodontal care in RA patients for improvement in the clinical parameters of RA and periodontal disease.

The short-term effect of anti-inflammatory agents dipyridamole and prednisone on the clinical presentation of periodontal disease, proinflammatory markers and serum levels of hs-CRP were investigated in periodontal patients. ${ }^{77}$ There was a significant reduction in hs-CRP, IFN- $\gamma$, and IL-6 in the treated group in response to anti-inflammatory agents. These markers of inflammation are also relevant to RA and cardiovascular disease, suggestive of common benefits from treatment of patients with coexisting diseases. AA-amyloidosis is a form of amyloidosis associated with serum amyloid A protein (SAA), an acute-phase protein. It causes reactive systemic amyloidosis. Secondary amyloidosis associated with SAA could occur in response to chronic inflammatory diseases such as RA, ankylosing spondylitis, Crohn's disease and ulcerative colitis resulting in extracellular deposits of amyloid proteins in various organs. The resultant secondary amyloidosis is associated with persistent levels of TNF- $\alpha$ leading to accumulation of amyloid in tissues. This amyloid consists of a serum amyloid P component, SAA, an acute phase protein and proteoglycans. Blockade of TNF- $\alpha$ with infliximab is able to overcome the poor prognosis previously associated with AA-amyloidosis. ${ }^{78}$

Adalimumab, an anti-TNF- $\alpha$ monoclonal antibody has been evaluated in several trials in RA, ankylosing spondylitis, psoriatic arthritis and juvenile idiopathic arthritis. Within a relatively short framework, these trials have shown improved disease control and quality of life for the patient with slower radiographic progression and an acceptable safety profile. ${ }^{79}$ An adverse side-effect relevant to the entire TNF- $\alpha$ blockade group is the reactivation of tuberculosis and an unproven putative link with malignant lymphoma. TNF-blockade appears to be effective in the management of adults with RA, atherosclerosis (AS), prostate-specific antigen (PsA), and children with JIA. It has been documented that its efficacy and safety profile are maintained throughout prolonged treatment schedules. Moreover, modulation of bone formation in inflammatory arthritis is a novel concept, which could provide new strategies for protection of bone from inflammation. The Wnt (a major class of secreted morphogenic ligands) signaling pathway associated with a network of proteins has emerged as a major link between inflammation and bone. Therapeutic targeting of these pathways would lead to more selective intervention relevant to pathological bone remodeling during inflammation, also relevant to periodontal diseases.

\section{Interaction of RANK-RANKL/ osteoprotegerin: therapeutic targets}

Globally prevalent bone related diseases such as osteoporosis and RA pose a substantial health care burden. A deeper understanding of the molecular mechanisms of bone metabolism has generated new strategies for their effective management. ${ }^{80}$ Coordinated actions of the TNF family of molecules, the receptor activator for nuclear factor (NF)- $\mathrm{\kappa B}$ (RANK), its ligand RANKL and osteoprotegerin (OPG) the decoy receptor of RANKL have been the hub of genetic experimentation in establishing their pivotal role as central regulators of osteoclast development and function. In addition, RANK-RANKL signaling also triggers crosstalk with other signaling pathways essential for refining homeostasis of pathophysiological mechanisms. They also play a vital role in establishing the thymic microenvironment and development of lymph nodes. 
Drug-targeting of the RANK-RANKL signaling pathways in osteoclasts would have significant impact on the management of diseases associated with bone loss such as arthritis, osteoporosis, periodontal diseases and metastases in cancer. Periodontal disease is characterized by inflammatory bone loss, common to RA and osteoporotic diseases. Lymphocytes and the cytokines released by these cells play a vital role in the etiopathogeneses of autoimmune diseases, due to their effects on osteoclast differentiation via modulation of the relative expression RANKL and OPG. ${ }^{81}$ Improved knowledge of cytokine interactions and cell signaling associated with bone loss could result in the development of novel therapeutic targets for the prevention of progressive bone loss in these disease entities.

Attenuation of osteoclast formation is a potential approach for reducing excessive bone resorption during inflammatory episodes. Osteoclast differentiation is modulated by signals critical for their differentiation and maturation such as cytokines, macrophage colony-stimulating factor (M-CSF) and receptor activator of RANKL. During the maturation process osteoclasts acquire specific markers, link with multinucleated giant cells and polarize on contacting bone. ${ }^{82}$ Several factors including osterix (SP7), a novel zinc-finger containing transcription factor that is essential for osteoblast differentiation and bone formation control proliferation and development of osteoblasts. Osteocytes which are differentiated osteoblasts embedded in bone matrix play an important role within bone as mechanosensors for the initiation of bone remodelling ${ }^{83}$ demonstrating coordinated activity between osteoblasts and osteoclasts in the turnover of bone. Local bone destruction is triggered by a common inflammatory pathway in the progression of inflammatory diseases such as RA, psoriatic arthritis and periodontal disease. During inflammation, homeostatic mechanisms that control bone turnover are disturbed resulting in osteoclast mediated bone resorption. ${ }^{84}$ A significant example of this is seen in RA, where prolonged, enhanced activity of the immune system results in massive bone destruction as a result of intense osteoclastic activity. The RANK-RANKL system is a major factor in osteoclast differentiation. ${ }^{85}$ Inflammation also disturbs the process of bone formation. The impact of inflammation on the Wnt signaling network involving a large number of proteins has important implications in the regulation of osteoblast differntiation and the subsequent formation of new bone, ${ }^{86}$ relevant to the management of RA and periodontitis.

An understanding of the significance of the RANKLRANK-osteoprotegerin (OPG) system was an important development in understanding bone biology. Disruption of this axis results in an imbalance between bone resorption and formation leading to altered homeostasis. RANKL, a member of the TNF superfamily is a surface molecule expressed on a range of cells, including activated $\mathrm{T}$ lymphocytes. It is induced in osteoblasts in equilibrium, in response to osteotrophic stimuli. ${ }^{87}$ RANKL is an essential prerequisite for osteoclast differentiation and bone resorptive actions. ${ }^{88-89}$ Proinflammatory cytokines such as IL-1, IL-6, IL-17, and TNF- $\alpha$ contribute to the initiation and enhancement of RANKL expression. ${ }^{90-92}$ An abundance of proinflammatory stimuli in chronic inflammatory conditions such as RA and periodontal disease could result in RANKL expression in activated T cells and synovial tissue components in RA. The interaction of the RANKL receptor with its ligand RANK is modulated by a secreted glycoprotein osteoprotegerin which suppresses osteoclast differentiation. ${ }^{93} \mathrm{OPG}$ is able to inhibit bone resorption and enhance bone mass by binding via its TNF receptor (TNFR) domains to TNF binding domains of its natural ligand RANKL. ${ }^{94}$ Several animal studies have demonstrated that recombinant OPG inhibits osteoclastogenesis and reduces bone erosion in treated cases of rodent arthritis models including TNF- $\alpha$ driven-, collagen inducedand adjuvant-induced arthritis. ${ }^{95-98}$ This has potential for therapeutic targeting in RA and adjunctive management of periodontitis.

It is relevant that the administration of OPG in animal models of periodontitis overcomes bone destruction. ${ }^{99}$ Periodontal disease is characterized by inflammation and bone loss. Proinflammatory molecules and cytokines such as IL-1 and TNF- $\alpha$ play primary roles in the inflammatory environment of periodontal lesions and trigger cells in the vicinity. A cascade of events leads to osteoclastogenesis and resultant bone loss via the RANK-RANKL-OPG axis. This process is relevant to pathological lesions driven by chronic inflammation. Documentation from diverse sources of experimentation on animal models of periodontitis have demonstrated that an elevated ratio of RANKL/OPG resulting from an increased RANKL mRNA expression leads to osteoclastogenesis and the loss of periodontal bone support. Studies of RANKL and OPG transgenic knockout mice demonstrate the relevance of these molecules in periodontal bone loss. A reduction in $\mathrm{RANKL/OPG}$ ratio and amelioration of bone loss is a desirable end point of periodontal therapy. ${ }^{83}$ Regulation of the RANK-RANKL-OPG axis is a realistic goal for periodontal therapeutic intervention.

A recent study was carried out to explore the mechanism by which microstructured Ti surfaces mediate stimulatory effects on OPG expression. ${ }^{100}$ Human osteoblast-like MG63 cells 
were cultured on sandblasted/acid etched and plasma sprayed Ti surfaces. Regulation of OPG production was determined by TGF- $\beta 1$, protein kinase $C$ and $\alpha 2 \beta 1$-integrin signaling. Osteoblasts grown on both $\mathrm{Ti}$ surfaces showed increased protein kinase $\mathrm{C}$ and TGF- $\beta 1$ activity with enhanced production of OPG. These activities were inhibited by a protein kinase inhibitor and blocking antibodies respectively; reduced OPG production was also demonstrated in integrin knockout mice. These findings are suggestive of the regulation of substrate-dependent OPG production by TGF- $\beta 1$, protein kinase $C$ and $\alpha 2 \beta 1$-integrin, via a mechanism by which protein kinase $C$ is increased by $\alpha 2 \beta 1$-integrin, resulting in stimulation of TGF- $\beta 1$ synthesis which in turn acts on its receptor to increase transcription of $\mathrm{OPG}$.

Therapeutic targeting of the RANKL-RANK-OPG signaling system in human inflammatory diseases has attracted considerable interest in view of its central role in mediating bone pathology. The anti-RANKL antibody has shown potential in reducing post-menopausal bone resorption. ${ }^{101-102}$ No major adverse side effects have been reported and it has potential as an effective therapeutic tool in the treatment of inflammatory bone disease. A recent study on the effects of denosumab, a monoclonal antibody that specifically targets RANKL, in local bone erosions in arthritis is suggestive of the reduction in bone erosions with no significant impact on disease activity in arthritis. ${ }^{103}$

\section{The role of interleukin- $I 7$ as a potential therapeutic target}

The proinflammatory cytokine IL-17 is secreted by the CD4+ Th17 subset, distinct from the classic Th1 and Th2 lineages. IL-17 is known to contribute to bone loss in RA and severe periodontal disease, and also plays an essential role in host defenses against pathogens that are susceptible to polymorphonuclear leukocytes (PMNs). These dual functions are borne out in its controversial role in the pathogenesis of chronic periodontal disease, initiated by anaerobic periodontal pathogens such as $P$. gingivalis. Raised levels of IL-17 are detected in humans with severe chronic periodontal disease. Female mice lacking the IL-17 receptor are significantly more susceptible to periodontal bone loss due to defective actions in the chemokine-PMN axis. Mice with the targeted deletion in the IL-17 receptor showed increased alveolar bone destruction on introduction of $P$. gingivalis in an acute periodontal infection model. ${ }^{104}$ It is relevant that female mice were more susceptible to periodontal bone loss than males in response to IL-17 and infection with $P$. gingivalis. ${ }^{105}$ There appear to be gender-dependent differences in IL-17 signaling associated with variations in chemokine production, IgG formation against $P$. gingivalis, and the upregulation of granulocyte colony stimulating factor between male and female mice, that account for these differences. This has implications in testing out anti-IL-17 biological therapies in this context. It is significant that although IL-17 mediates destructive inflammation under certain conditions, it could also play a role in host defense.

A significant impact on bone metabolism and the pattern of bone loss are seen in chronic inflammatory diseases such as periodontal disease, RA, and ankylosing spondylitis. The link between inflammation and bone metabolism are increasingly documented in the literature. A better understanding of molecular mechanisms involved has lead to the development of novel therapeutic targets for the management of inflammatory bone loss. ${ }^{106}$ This approach includes the use of blocking agents against TNF- $\alpha$, neutralizing antibodies against proinflammatory cytokines such as IL-6, IL-17, and other targets that require further research. The roles of IL-6, IL-17, and TNF- $\alpha$ in chronic inflammation are very closely coordinated and there is increasing evidence of the role of IL-17 in the inflammatory pathogenesis of arthritis, atherosclerosis ${ }^{107,108}$ and periodontitis, which were previously attributed mainly to excessive levels of TNF- $\alpha$ and IL-6. The role of IL-17 in periodontal and systemic diseases has been reviewed recently ${ }^{109}$ reinforcing these concepts. Analysis of human synovial and serum samples show elevated levels of IL-17 in inflammatory and autoimmune diseases such as periodontitis ${ }^{110-111} \mathrm{RA}^{112}$ and inflammatory bowel disease. ${ }^{113}$

There is recent documentation of the bone remodeling capacity of IL-17, along with other inflammatory cytokines, thus favoring bone loss. It can modulate the RANKL/OPG ratio by increasing RANKL expression with a concomitant decrease in OPG expression in osteoblastic cells both in vivo and in vitro leading to the increased formation of osteoclasts and bone erosion in a mouse model of arthritis. ${ }^{114,115}$ The critical role of IL-17 in infection needs to be borne in mind when considering IL-17 anticytokine therapy in view of the possible deleterious consequences related to neutrophil recruitment and compromised host defenses. Distinct signaling outcomes may be associated with diverse IL-17 receptor complexes. Further work is required to determine which receptor complex isoforms are most relevant to the actions of IL-17. Therapeutic agents that antagonize signaling via the IL-17 receptor complex may serve as useful treatment options where there is lack of response to other available regimens.

A hyper-responsive immune status which could result in unresolved inflammation, characterizes chronic inflammatory 
periodontal disease and RA. Proinflammatory cytokines fuel inflammation. A novel subset of T-helper cells plays a central role in inflammation and autoimmune diseases. They release several cytokines including IL-17. Modulation of the IL-17 signaling complex has potential as a therapeutic target to attenuate overexuberant inflammation attributed to several local inflammatory conditions such as periodontitis RA and critical systemic pathologies such as diabetes, chronic obstructive pulmonary disease and cardiovascular disease. ${ }^{109}$ However, all inflammatory conditions may not respond to this approach. More work in this field needs to identify means by which therapeutic targets directed at attenuating inflammation and bone loss relevant to periodontal disease progression and other systemic diseases would provide a refined therapeutic strategy for disease control. This could have wider applications for diseases driven predominantly by a robust inflammatory response and autoimmunity.

\section{Recent advances in neutralizing the IL-6 pathway in arthritis}

The cytokine IL-6 plays a key role in the induction of CRP. IL-6 is pivotal in the progression of RA as well as in systemic bone loss and osteoporosis. A major role for IL-6 as a proinflammatory cytokine driving inflammatory bone loss is well documented. IL-6 blockade with the IL-6-receptor specific antibody tocilizumab is effective in blocking inflammatory bone loss in RA as well as clinical signs and symptoms. ${ }^{116}$ Potential therapeutic targets for RA in this context are many considering the coordinated activity between several cytokines. The most promising results have been documented for inhibition of TNF- $\alpha$.

The inflammatory component of RA is characterized by raised serum and synovial fluid levels of IL-6 and increased IL-6/IL-6R/glycoprotein-130-mediated trans-signaling. ${ }^{117}$ Results of the neutralization of IL-6-mediated signaling by using anti-IL-6 antibodies in 4 clinical trials have provided compelling evidence of the significant clinical benefit to those who showed limited responses to corticosteroids, diseasemodifying antirheumatic drugs or anti-TNF-therapy. There are critical issues with regard to the modulation of IL-6targeted therapy in view of the simultaneous blockade of other members of the IL- 6 cytokine family and its consequences. Upregulation of IL-6 expression has also been reported in the development of osteoarthritis in animals.

The soluble form of IL-6 receptor acts as an agonist for signal transmission via interaction with the transmembrane glycoprotein gp $130^{118}$ which participates in the formation of high affinity IL-6 receptors. Monoclonal antibodies directed against gp130, inhibit IL-6 function. Synthesis of a recombinant soluble gp130 protein to suppress IL-6 transsignaling would be a novel target for neutralization of the IL-6 pathway and could well become the next generation of drug development. A recent study ${ }^{119}$ demonstrated that when in vitro monocyte cultures were stimulated with RANKL or in combination with TNF- $\alpha$, IL-6 receptor blockade with a murine anti-IL-6R antibody, directly reduced osteoclast differentiation and bone resorption. In humans IL-6 blockade reduced osteoclast development and bone erosion without affecting joint inflammation, which is suggestive of the effects of anti-IL-6 therapy against osteoclasts being independent of its anti-inflammatory actions. These actions could potentially control inflammatory bone loss seen in chronic periodontitis, with a plausible target for atherosclerosis fuelled by cytokines including IL-6.

\section{Emerging roles of ADAMTS-7 and ADAMTS- I 2 matrix metalloproteinases}

The ADAMTS (a disintegrin and a metalloproteinase domain with thrombospondin motifs) proteases are of biological relevance in view of their high prevalence at disease targets. They constitute a disintegrin and zinc matrix metalloproteinases with thrombospondin motifs endowing them with features of both proteinases and adhesion molecules. They display a wide spectrum of biological effects including cell fusion, cell adhesion, shedding process, cleavage of various substrates from extracellular matrices, growth factors and cytokines. Overexpression of these proteases leads to dysregulation of tissue homeostasis and distinct pathologies, which makes them a potential therapeutic target for disease control. ${ }^{120,121}$

ADAMTS-1 could contribute to atherosclerosis by cleaving versican, an extracellular matrix component, and mutations in ADAMTS-1 have been associated with the increased risk of coronary artery disease. ${ }^{122}$ Formation of atherosclerotic plaque and atherothrombotic disease have been attributed to ADAMTS-4 and -8. ${ }^{123,124}$ ADAMTS-7 and ADAMTS-12, the two recently discovered members of the family form a subgroup within the ADAMTS family based on shared domains. Recent documentation underscores their importance in the pathogenesis of arthritis and atherosclerosis. ${ }^{63,125}$ The key role of matrix metalloproteinases (MMPs) and ADAMTSs in osteoarthritis and RA is well established. ${ }^{126-128}$ It has been demonstrated in arthritic cartilage and synovium that ADAMTS-7 is significantly upregulated in comparison with healthy controls. Several MMPs involved in the initiation and progression of arthritis are induced by the inflammatory 
cytokines TNF- $\alpha$ and IL- $1 \beta^{129,130}$ Analysis of cultured human cartilage implants using real-time polymerase chain reaction (PCR) show significant induction of ADAMTS-7 and ADAMTS-12 expression by both TNF- $\alpha$ and IL-1 $\beta .{ }^{131}$

It is relevant that ADAMTS-7 and its ability to interact with cartilage oligometric matrix protein (COMP), a prominent noncollagenous component of cartilage extracellular matrix, also have implications in atherosclerosis and the progression of vascular diseases, associated with the migration of vascular smooth muscle cells, requiring protease mediated degradation of extracellular matrix. ${ }^{132,133}$ The presence of COMP in atherosclerotic lesions implies its involvement in the process. ADAMTS-7 and -12 also play an important role in several other diseases, including arthritis, atherosclerosis and cancer. Interactive pathways of progression relevant to diverse diseases could improve our understanding of disease pathogenesis and also provide effective therapeutic targets which could have a common benefit when relevant diseases may coexist in the same individual, including chronic periodontitis.

\section{Potential for simvastatin as an anti-inflammatory and proanabolic agent}

Statins such as simvastatin are 3-hydroxy-3-methylglutaryl co-enzyme A (HMGCoA) reductase inhibitors that decrease the synthesis of cholesterol. They exert anti-inflammatory and immunomodulatory actions independent of cholesterol lowering effects in addition to reducing the risk of cardiovascular disease in susceptible patients, mainly by lowering plasma lipid concentration. ${ }^{134,135}$ They have been shown to be effective in suppressing lipopolysaccharides-stimulated MMP-1, MMP-8, and MMP-9 in mononuclear cells. ${ }^{136}$ Simvastatin has been shown to be protective against periodontal attachment loss and bone loss in ovariectomized rats ${ }^{137}$ and could contribute to bone augmentation in an enclosed alveolar environment. ${ }^{138}$ Simvastatin also stimulates osteoblastic function and alveolar bone formation when applied topically. ${ }^{139}$

In view of the association between chronic low grade inflammatory processes in periodontitis and cardiovascular disease and in the management of the latter with statins, the effect of statins on markers of periodontal inflammation was investigated. ${ }^{140}$ It is relevant that there was a significant reduction in periodontal inflammatory damage in statin users; their anti-inflammatory effects could account for these findings. Several of these universal anti-inflammatory effects of statins are mediated via inhibition of isoprenoids which function as lipid attachments for intracellular signaling, ${ }^{141,142}$ improving endothelial function, enhancing the stability of atherosclerotic plaque, together with decreasing inflammation and oxidative stress. ${ }^{143}$ These mechanisms are of particular importance in preventing the risk of coronary artery disease with implications in the management of RA and periodontitis.

\section{Summary and conclusions}

Our understanding of the pathogenesis of atherosclerosis has evolved from a lipid deposition disorder to a focal, chronic inflammatory disease affecting arteries, characterized by inflammatory plaques susceptible to rupture and thrombosis. Atherogenesis shares certain pathological features with other inflammatory diseases including autoimmune RA and chronic periodontitis. Common features include macrophageactivating cytokines such as TNF- $\alpha$, IL-1 and IL-6, the presence of CD $4{ }^{+} \mathrm{CD} 28^{-}$regulatory T-cells, raised inflammatory markers including CRP and the enhanced expression of endothelial adhesion molecules including VCAM-1, providing a common nucleus for disease control with focused therapeutic targeting. However, the association between atherosclerosis and RA extends beyond common pathogenic mechanisms. Standardized mortality ratios for cardiovascular disease in RA range from 1.2 to 5 , and cardiovascular death accounts for up to $50 \%$ of mortality with life expectancy reduced by 10-15 years. A similar trend observed in SLE, with a marked increase in stroke and myocardial infarction has been reported. This outcome data reflects the presence of increased carotid artery intima thickening, vascular stiffness and impaired flow-mediated vasodilation in RA and SLE, indicating endothelial dysfunction and subclinical atherosclerosis. The current challenge to clinicians is the development of treatment regimens that suppress underlying RA disease activity, inhibit endothelial dysfunction, retard the progression of atherosclerosis and effectively control periodontal disease progression with adjunctive therapies targeted at inflammatory excess addressed in this review. These inflammatory processes share common ground, providing targets for therapeutic intervention aimed at controlling an overexuberant immune response fuelled by cytokines and the side effects of a progressive pathogenesis.

\section{Disclosure}

The author report no conflicts of interest in this work.

\section{References}

1. Banks M, Flint J, Bacon P, Kitas G. Rheumatoid arthritis is an independent risk factor for ischemic heart disease. Arthritis Rheum. 2000; 43 (suppl):385. 
2. Solomon DH, Karlson EW, Rimm EB, et al. Cardiovascular morbidity and mortality in women diagnosed with rheumatoid arthritis. Circulation. 2003;107(9):1303-1307.

3. Van Doornum S, McNoll G, Wicks IP. Accelerated atherosclerosis: an extra-articular feature of rheumatoid arthritis. Arthritis Rheum. 2002;46(4):862-873

4. Lowe GDO, Danesh J. Classical and emerging risk factors for cardiovascular disease. Semin Vasc Med. 2005;2(3):229-445.

5. Abou-Raya A, Abou-Raya S. Inflammation: a pivotal link between autoimmune diseases and atherosclerosis. Autoimmun Rev. 2006;5(5): 331-337.

6. Abou-Raya S, Naim A, Abu-El KH, El BS. Coronary artery disease and periodontal disease: is there a link. Angiology. 2002;53(2): 141-148.

7. Rutger Persson G, Ohlsson O, Pettersson T, Renvert S. Chronic periodontitis, a significant relationship with acute myocardial infarction. Eur Heart J. 2003;24(23):2108-2115.

8. Malthaner SC, Moore S, Mills M. Investigation of the association between angiographically defined coronary artery disease and periodontal disease. J Periodontol. 2002;73(10):1169-1176.

9. Irwin CR, Myrillas TT, Traynor P, Leadbetter N, Cawston TE. The role of soluble interleukin (IL)-6 receptor in mediating the effects of IL-6 on matrix metalloproteinase-1 and tissue inhibitor of metalloproteinase-1 expression by gingival fibroblasts. J Periodontol. 2002;73(7): 741-747

10. Pihlstrom BL, Michalowicz BS, Johnson NW. Periodontal diseases Lancet. 2005;366(9499):1809-1820.

11. Taubman MA, Valverde P, Han X, Kawai T. Immune response: the key to bone resorption in periodontal disease. J Periodontol. 2005; 76 Suppl 11:2033S-2041S.

12. Gemmell E, Yamazaki K, Seymour GJ. Destructive periodontitis lesions are determined by the nature of the lymphocytic response. Crit Rev Oral Biol Med. 2002;13(1):17-34.

13. Kinane DF, Demuth DR, Gorr SU, Hajishengallis GN, Martin MH. Human variability in innate immunity. Periodontol 2000. 2007;45(1): 14-34.

14. Firestein GS. Aetiology and pathogenesis of rheumatoid arthritis. In: Kelley WN, Harris ED Jr, Ruddy S, Sledge CB eds. Textbook of Rheumatology. 6th ed. Philadelphia, PA: Saunders;2001: 921-966.

15. Darveau RP, Tanner A, Page RC. The microbial challenge in periodontitis. Periodontol. 2000.1997;14(1):12-32.

16. Brown LJ, Loe H. Prevalence, extent, severity and progression of periodontal disease. Periodontol. 2000;1993;2(1):57-71.

17. Libby P, Ridker P, Maseri A. Inflammation and atherosclerosis. Circulation. 2002;105(9):1135-1143.

18. Mercado FB, Marshall RI, Klestov AC, Bartold PM. Relationship between rheumatoid arthritis and periodontitis. J Periodontol. 2001;72(6):779-787.

19. Abou-Raya A, Abou-Raya S. Periodontal disease and rheumatoid arthritis: is there a link. Scand J Rheum. 2005;34(5):408-410.

20. Soory M. Periodontal diseases and rheumatoid arthritis: A coincident model for therapeutic intervention. Curr Drug Metab. 2007;8(8): 750-757.

21. Abou-Raya S, Abou-Raya A, Naim A, Abuelkheir H. Rheumatoid arthritis, periodontal disease and coronary artery disease. Clin Rheumatol. 2008;27(4):421-427.

22. Page RC, Eke PI. Case definitions for use in population-based surveillance of periodontitis. J Periodontol. 2007;78(7):1387-1399.

23. Hamdulay SS, Mason JC. Disease-modifying anti-rheumatic drugs do they reduce cardiac complications of RA? Heart. 2009;95(18): 1502-1507.

24. Wu B, Fukuo K, Suzuki K, Yoshino G, Kazumi T. Relationships of systemic oxidative stress to body fat distribution, adipokines and inflammatory markers in healthy middle aged women. Endocr J. 2009;56(6):773-782.

25. Madan JC, Davis JM, Craig WY, et al. Maternal obesity and markers of inflammation in pregnancy. Cytokine. 2009;47(1):61-64.
26. Derosa G, Ferrari I, D'Angelo A, et al. Oral fat load effects on inflammation and endothelial stress markers in healthy subjects. Heart Vessels. 2009;24(3):204-210.

27. Rahman ZA, Soory M. Antioxidant effects of glutathione and IGF in a hyperglycaemic cell culture model of fibroblasts: some actions of advanced glycaemic end products (AGE) and nicotine. Endocr Metab Immune Disord Drug Targets. 2006;6(3):279-286.

28. Figuero-Ruiz E, Soory M, Cerero R, Bascones A. Oxidant / antioxidant interactions of nicotine, Coenzyme Q10, Pycnogenol and phytoestrogens in oral periosteal fibroblasts and MG63 osteoblasts, Steroids. 2006;71(13-14):1062-1072.

29. Soory M. A role for non-antimicrobial actions of tetracyclines in combating oxidative stress in periodontal and metabolic diseases. Open Dent J. 2008;2:5-12.

30. Soory M. Redox status in periodontal and systemic inflammatory conditions including associated neoplasias: Antioxidants as adjunctive therapy? Infect Disord Drug Targets. 2009;9(Suppl):415-427.

31. Sørensen LK, Havemose-Poulsen A, Bendtzen K, Holmstrup P. Aggressive periodontitis and chronic arthritis: blood mononuclear cell gene expression and plasma protein levels of cytokines and cytokine inhibitors. J Periodontol. 2009;80(2):282-289.

32. Schett G, Redlich K, Xu Q, et al. Enhanced expression of heat shock protein 70 (hsp70) and heat shock factor 1 (HSF1) activation in rheumatoid arthritis synovial tissue. Differential regulation of hsp70 expression and hsf1 activation in synovial fibroblasts by proinflammatory cytokines, shear stress, and antiinflammatory drugs. J Clin Invest.1998;102(2):302-311.

33. Bain J, Lester SR, Henry WD, et al. Comparative gender differences in local and systemic concentrations of pro-inflammatory cytokines in rats with experimental periodontitis, J Periodont Res. 2009; 44(1):133-140.

34. Soory M. Biomarkers of diabetes mellitus and rheumatoid arthritis associated with oxidative stress, applicable to periodontal diseases. Curr Topics Ster Res. 2004;4:1-17.

35. Liao F, Li Z, Wang Y, Shi B, Gong Z, Cheng X. Porphyromonas gingivalis may play an important role in the pathogenesis of periodontitis-associated rheumatoid arthritis. Med Hypothesis. 2009;72(6):732-735.

36. Behl Y, Siqueira M, Ortiz J, et al. Activation of the acquired immune response reduces coupled bone formation in response to a periodontal pathogen. J Immunol. 2008;181(12);8711-8718.

37. Mikuls TR, Payne JB, Reinhardt RA, et al. Antibody responses to Porphyromonas gingivalis ( $P$. gingivalis) in subjects with rheumatoid arthritis and periodontitis. Int Immunopharmacol. 2009;9(1):38-42.

38. Al-Katma MK, Bissada NF, Bordeaux JM, Sue J, Askari AD. Control of periodontal infection reduces the severity of active rheumatoid arthritis. J Clin Rheumatol. 2007;13(3):134-137.

39. Ogrendik M. Periodontopathic bacteria and rheumatoid arthritis: is there a link? J Clin Rheumatol. 2008;14(5):310-311.

40. Moen K, Brun JG, Valen M, et al. Synovial inflammation in active rheumatoid arthritis and psoriatic arthritis facilitates trapping of a variety of oral bacterial DNAs. Clin Exp Rheumatol. 2006;24(6):656-663.

41. McGraw WT, Potempa J, Farley D, Travis J. Purification, characterization, and sequence analysis of a potential virulence factor from Porphyromonas Gingivalis, peptidylarginine deiminase. Infect Immun. 1999;67(7):3248-3256.

42. Pischon N, Roehner E, Hocke A, et al. Effects of porphyromonas gingivalis on cell cycle progression and apoptosis of primary human chondrocytes. Ann Rheum Dis. 2009;68(12):1902-1907.

43. Cuesta IA, Sud S, Song Z, et al. T-cell receptor (Vbeta) bias in the response of rheumatoid arthritis synovial fluid $\mathrm{T}$ cells to connective tissue antigens. Scand J Rheumatol. 1997;26(3):166-173.

44. Leung KP, Torres BA. Prevotella intermedia stimulates expansion of Vbeta-specific CD4(+) T cells. Infect Immun. 2000;68(9):5420-5424.

45. Gibson FC 3rd, Genco CA. Porphyromonas Gingivalis mediated periodontal disease and atherosclerosis: disparate diseases with commonalities in pathogenesis through TLRs. Curr Pharm Des. 2007; 13(36):3665-3675. 
46. Galkina E, Ley K. Immune and Inflammatory Mechanisms of Atherosclerosis. Annu Rev Immunol. 2009;27:165-197.

47. Soory M. Relevance of dyslipidemia and its consequences in periodontal patients with co-existing cardiovascular disease and diabetes mellitus: Therapeutic targets. Recent Patents on Endocrine, Metabolic and Immune Drug Discovery. 2009;3(3):214-224.

48. Rizzo M, Spinas GA, Cesur M, Ozbalkan Z, Rini GB, Berneis K. Atherogenic lipoprotein phenotype and LDL size and sub classes in drug-naïve patients with early rheumatoid arthritis. Atherosclerosis. 2009;207(2):502-506.

49. Nilsson M, Kopp S. Gingivitis and periodontitis are related to repeated high levels of circulating tumour necrosis factor-alpha in patients with rheumatoid arthritis. J Periodontol. 2008;79(9):1689-1696.

50. Pischon N, Pischon T, Kröger J, et al. Association among rheumatoid arthritis, oral hygiene and periodontitis. J Periodontol. 2008; 79(6):979-986.

51. Smolik I, Robinson D, El-Gabalawy HS. Periodontitis and rheumatoid arthritis: epidemiologic, clinical and immunologic associations. Compend Contin Educ Dent. 2009;30(4):188-190.

52. Soory M. Relevance of nutritional antioxidants in metabolic syndrome, ageing and cancer: Potential for therapeutic targeting. Infect Disord Drug Targets. 2009;9(4):400-414

53. de Pablo P, Chapple IL, Buckley CD, Dietrich T. Periodontitis in systemic rheumatic diseases. Nat Rev Rheumatol. 2009;5(4):218-224.

54. Modi DK, Chopra VS, Bhau U. Rheumatoid arthritis and periodontitis: biological links and the emergence of dual purpose therapies. Indian $J$ Dent Res. 2009;20(1):86-90.

55. Stamatelopoulos KS, Kitas GD, Papamichael CM, et al. Oral health and orthodontic considerations in children with idiopathic arthritis: review of the literature and report of a case. J Ir Dent Assoc. 2008; 54(1):29-36.

56. Leksell E, Ernberg M, Magnusson B, Hedenberg-Magnusson B. Intraoral condition in children with juvenile idiopathic arthritis compared to controls. Int J Paediatr Dent. 2008;18(6):423-433.

57. Reichert S, Stein J, Fuchs C, John V, Schaller HG, Machulla HK. Are there common human leucocyte antigen associations in juvenile idiopathic arthritis and periodontitis? J Clin Periodontol. 2007;34(6): 492-498.

58. Abou-Raya S, Abou-Raya A, Naim A, Abuelkheir H. Chronic inflammatory autoimmune disorders and atherosclerosis. Ann NY Acad Sci. 2007; 1107:56-67.

59. Stamatelopoulos KS, Kitas GD, Papamichael CM, et al. Atherosclerosis in Rheumatoid Arthritis Versus Diabetes. A Comparative Study. Arterioscler Thromb Vasc Biol. 2009;29(1):1-7.

60. Targon'ska-Ste pniak B, Dryglewska M, Majdan M. Adiponectin and lipid serum concentrations in patients with rheumatoid arthritis. Rheumatol Int. 2009:30(6):731-737.

61. Wang L, Zheng J, Bai X, et al. ADAMTS-7 mediates vascular smooth muscle cell migration and neointima formation in balloon-injured rat arteries. Circ Res. 2009;104(5):688-698.

62. Wang S, Yiu KH, Mok MY, et al. Prevalence and extent of calcification over aorta, coronary and carotid arteries in patients with rheumatoid arthritis. J Intern Med. 2009;266(5):445-452.

63. Tanasescu C, Jurcut C, Jurcut R, Ginghina C. Vascular disease in rheumatoid arthritis: from subclinical lesions to cardiovascular risk. Eur J Intern Med. 2009;20(4):348-354.

64. Yao Z, Yang J, Pan L, Chen Z. Periodontal treatment: potential to reduce cardiovascular morbidity and / mortality. Med Hypotheses. 2009; 73(1):33-35.

65. Eley BM, Soory M, Manson D. The effect of systemic factors on the periodontal tissues. In: Periodontics. 6th ed. Amsterdam. The Netherlands: Elsevier; 2010:107-125.

66. Monteiro AM, Jardini MA, Alves S, et al. Cardiovascular disease parameters in periodontitis. J Periodontol. 2009;80(3):378-388.

67. Fentog lu O, Oz G, Taşdelen P, Uskun E, Aykaç Y, Bozkurt FY. Periodontal status in subjects with hyperlipidemia. J Periodontol. 2009; 80(2):267-273.
68. Banihashemrad SA, Moeintaghavi A, Rafighdoost A. Relationship between cholesterol and triglyceride blood values and periodontal parameters in patients of Mashhad health centre. NY State Dent J. 2008;74(5):65-66.

69. McInnes IB, Schett G. Cytokines in the pathogenesis of rheumatoid arthritis. Nat Rev Immunol. 2007;7(6):429-442.

70. Scott DL, Kingsley GH. Tumor necrosis factor inhibitors for rheumatoid arthritis. N Engl J Med. 2006;355(7):704-712.

71. Keystone EC. Strategies to control disease in rheumatoid arthritis with tumor necrosis factor antagonists-an opportunity to improve outcomes. Nat Clin Pract Rheumatol. 2006;2(11):594-601.

72. Seriolo B, Paolino S, Sulli A, Ferretti V, Cutolo M. Bone metabolism changes during anti-TNFalpha therapy in patients with active rheumatoid arthritis. Ann N Y Acad Sci. 2006;1069:420-427.

73. Sakai Y, Sakai S, Otsuka T, et al. Efficacy of high-throughput leukocytapheresis for rheumatoid arthriris with a reduced response to infliximab. Ther Apher Dial. 2009;13(3):179-185.

74. Pers JO, Sarau A, Pierre R, Youinou P. Anti-TNF- $\alpha$ immunotherapy is associated with increased gingival inflammation without clinical attachment loss in subjects with rheumatoid arthritis. $J$ Periodontol. 2008;79(9):1645-1651.

75. Mayer Y, Balbir-Gurman A, Machtei E. Anti-tumour necrosis factoralpha therapy and periodontal parameters in patients with rheumatoid arthritis. J Periodontol. 2009;80(9):1414-1420.

76. Oritz P, Bissada NF, Palomo L, et al. Periodontal therapy reduces the severity of active rheumatoid arthritis in patients treated with or without tumour necrosis factor inhibitors. J Periodontol. 2009;80(4):535-540.

77. Renvert S, Lindahl C, Roos-Jansaker AM, Lessem J. Short-term effects of an anti-inflammatory treatment on clinical parameters and serum levels of C-reactive protein and pro-inflammatory cytokines in subjects with periodontitis. J Periodontol. 2009;80(6):892-900.

78. Keersmaekers T, Claes K, Kuypers DR, de Vlam K P, Verschueren P, Westhovens R. Long-term efficacy of infliximab treatment for AAamyloidosis secondary to chronic inflammatory arthritis. Ann Rheum Dis. 2009;68(5):759-761.

79. Papagoras C, Voulgari PC, Drosos AA. Long-term use of adalimumab in the treatment of rheumatic diseases. Open Access Rheumatol Res Rev. 2009;1:51-68

80. Leibbrandt A, Penninger JM. RANK/RANKL: Regulators of immune responses and bone physiology. Ann NY Acad Sci. 2008;1143:123-150.

81. Horwood N. Lymphocyte-derived cytokines in inflammatory arthritis. Autoimmunity. 2008;41(3):230-238.

82. Teitelbaum SL. Osteoclasts: what do they do and how do they do it? Am J Pathol. 2007;170(2):427-435.

83. Cochran DL. Inflammation and bone loss in periodontal disease. J Periodontol. 2008;79(8):1569-1576.

84. Schett G. Cells of the synovium in rheumatoid arthritis. Osteoclasts. Arthritis Res Ther. 2007;9(1):203-208.

85. Boyle WJ, Simonet WS, Lacey DL. Osteoclast differentiation and activation. Nature. 2003;423(6937):337-342.

86. Johnson ML, Kamel MA. The Wnt signaling pathway and bone metabolism. Curr Opin Rheumatol. 2007;19(4):376-382.

87. Takahashi N, Udagawa N, Kobayashi Y, Suda T. Generation of osteoclasts in vitro, and assay of osteoclast activity. Methods Mol Med. 2007; 135:285-301.

88. Gravallese EM, Manning C, Tsay A, et al. Synovial tissue in rheumatoid arthritis is a source of osteoclast differentiation factor. Arthritis Rheum. 2000;43(2):250-258.

89. Shigeyama Y, Pap T, Kunzler P, Simmen BR, Gay RE, Gay S. Expression of osteoclast differentiation factor in rheumatoid arthritis. Arthritis Rheum. 2000;43(11):2523-2530.

90. Lam J, Takeshita S, Barker JE, Kanagawa O, Ross FP, Teitelbaum SL. TNF-alpha induces osteoclastogenesis by direct stimulation of macrophages exposed to permissive levels of RANK ligand. J. Clin Invest. 2000;106(12):1481-1488. 
91. Wei S, Kitaura H, Zhou P, Ross FP, Teitelbaum SL. IL-1 mediates TNF-induced osteoclastogenesis. J Clin Invest. 2005;115(2):282-290.

92. Wong PK, Quinn JM, Sims NA, van Nieuwenhuijze A, Campbell IK, Wicks IP. Interleukin-6 modulates production of T lymphocyte-derived cytokines in antigen-induced arthritis and drives inflammation-induced osteoclastogenesis. Arthritis Rheum. 2006;54(1):158-168.

93. Morony S, Warmington K, Adamu S, et al. The inhibition of RANKL causes greater suppression of bone resorption and hypercalcemia compared with bisphosphonates in two models of humoral hypercalcemia of malignancy. Endocrinol. 2005;146(8):3235-3243.

94. Schneeweis LA, Willard D, Milla ME. Functional dissection of osteoprotegerin and its interaction with receptor activator of NF-kappaB ligand. J Biol Chem. 2005;280(50):41155-41164.

95. Schett G, Middleton S, Bolon B, et al. Additive bone-protective effects of anabolic treatment when used in conjunction with RANKL and tumor necrosis factor inhibition in two rat arthritis models. Arthritis Rheum. 2005;52(5):1604-1611.

96. Redlich K, Hayer S, Maie A, et al. Tumor necrosis factor alphamediated joint destruction is inhibited by targeting osteoclasts with osteoprotegerin. Arthritis Rheum. 2002;46(3):85-792.

97. Redlich K, Görtz B, Hayer S, et al. Repair of local bone erosions and reversal of systemic bone loss upon therapy with anti-tumor necrosis factor in combination with osteoprotegerin or parathyroid hormone in tumor necrosis factor-mediated arthritis. Am J Pathol. 2004;164(2): 543-555.

98. Romas E, Sims NA, Hards D, et al. Osteoprotegerin reduces osteoclast numbers and prevents bone erosion in collagen-induced arthritis. Am J Pathol. 2002;161(4):1419-1427.

99. Jin Q, Cirelli JA, Park CH, et al. RANKL Inhibition through osteoprotegerin blocks bone loss in experimental periodontitis. J Periodontol. 2007;78(7):1300-1308

100. Schwartz Z, Olivares-Navarrete R, Wieland M, Cochran DL, Boyan $\mathrm{BD}$. Mechanisms regulating increased production of osteoprotegerin by osteoblasts cultured on microstructured titanium surfaces. Biomaterials. 2009;30(20):3390-3396.

101. Bekker PJ, Holloway DL, Rasmussen AS, et al. A single-dose placebo-controlled study of AMG 162, a fully human monoclonal antibody to RANKL, in postmenopausal women. J Bone Miner Res. 2004;19(7):1059-1066.

102. McClung MR, Lewiecki EM, Cohen SB, et al. Denosumab in postmenopausal women with low bone mineral density. $N$ Engl J Med. 2006;354(8):821-831.

103. Cohen SB, Valen PA, Richlin C. RANKL inhibition with denosumab reduces progression of bone erosions in patients with rheumatoid arthritis: month 6 MRI results. Arthritis Rheum. 2006;54:S831-S836.

104. Yu JJ, Ruddy MJ, Wong GC, et al. An essential role for IL-17 in preventing pathogen-initiated bone destruction: recruitment of neutrophils to inflamed bone requires IL-17 receptor-dependent signals Blood. 2007;109(9):3794-3802.

105. Yu JJ, Ruddy MJ, Conti HR, Boonanantanasarn K, Gaffen SL. The interleukin-17 receptor plays a gender-dependent role in host protection against Porphyromonas gingivalis-induced periodontal bone loss. Infect Immun. 2008;76(9):4206-4213.

106. Herman S, Krönke G, Schett G. Molecular mechanisms of inflammatory bone damage: emerging targets for therapy. Trends Mol Med. 2008;14(6):245-253.

107. Gabay C, McInnes B. The biological and clinical importance of the new generation cytokines in rheumatic diseases. Arthritis Res Ther. 2009;11(3):230-243.

108. von der Thusen JH, Kuiper J, van Berkel TJ, Biessen EA. Interleukins in atherosclerosis: Molecular pathways and therapeutic potential. Pharmacol Rev. 2003;55(1):133-166.

109. Kramer JM, Gaffen SL. Interleukin-17: a new paradigm in inflammation, autoimmunity and therapy. J Periodontol. 2007;78(6):1083-1093.

110. Takahashi K, Azuma T, Motohira H, Kinane DF, Kitetsu S. The potential role of interleukin-17 in the immunopathology of periodontal disease. J Clin Periodontol. 2005;32(4):369-374.
111. Vernal R, Dutzan N, Chaparro A, Puente J, Valenzuela MA, Gamonal J. Levels of interleukin-17 in gingival crevicular fluid and in supernatants of cellular cultures of gingival tissue from patients with chronic periodontitis. J Clin Periodontol. 2005;32(4):383-389.

112. Kotake S, Udagawa N, Takahashi N, et al. IL-17 in synovial fluids from patients with rheumatoid arthritis is a potent stimulator of osteoclastogenesis. J Clin Invest. 1999;103(9):1345-1352.

113. Zhang Z, Zheng M, Bindas J, Schwarzenberger P, Kolls JK. Critical role of IL-17 receptor signaling in acute TNBS induced colitis. Inflamm Bowel Dis. 2006;12(5):382-388.

114. Lubberts E, van den Bersselaar L, Oppers-Walgreen B, et al. IL-17 promotes bone erosion in murine collagen-induced arthritis through loss of the receptor activator of NF-kappaB ligand/osteoprotegerin balance. J Immunol. 2003;70(5):2655-2662.

115. Nakashima T, KobayashiY, Yamasaki S, Kawakami A, Eguchi K, Sasaki H. Protein expression and functional difference of membrane bound and soluble receptor activator of NF-kappaB ligand: Modulation of the expression by osteotropic factors and cytokines. Biochem Biophys Res Commun. 2000;275(3):768-775.

116. Maini RN, Taylor PC, Szechinski J, et al. Double-blind randomized controlled clinical trial of the interleukin- 6 receptor antagonist, tocilizumab, in European patients with rheumatoid arthritis who had an incomplete response to methotrexate. Arthritis Rheum. 2006;54(9):2817-2829.

117. Malemud CJ. Recent advances in neutralizing the IL-6 pathway in arthritis. Open Access Rheumatol Res Rev. 2009;1:133-150.

118. Visvanathan S, van der Heijde D, Deodhar A, et al. Effects of infliximab on markers of inflammation and bone turnover and associations with bone mineral density in patients with ankylosing spondylitis. Ann Rheum Dis. 2009;68(2):175-182.

119. Axmann R, Bohm C, Kronke G, Zwerina J, Smolen J, Schett G. Inhibition of interleukin-6 receptor directly blocks osteoclast formation in vitro and in vivo. Arthritis Rheum. 2009;60(9):2747-2756.

120. Lin AE, Liu C-J. The emerging roles of ADAMS-7 and ADAMS-12 matrix metalloproteinases. Open Access Rheumatol Res Rev. 2009;1:121-131.

121. Paulissen G, Rocks N, Gueders MM, et al. Role of ADAM and ADAMTS metalloproteinases in airway diseases. Resp Res. 2009;10(1):127-138.

122. Sabatine MS, Ploughman L, Simonsen KL, et al. Association between ADAMTS1 matrix metalloproteinase gene variation, coronary heart disease, and benefit of statin therapy. Arterioscler Thromb Vasc Biol. 2008;28(3):562-567.

123. Wagsater D, Bjork H, Zhu C, et al. ADAMTS-4 and -8 are inflammatory regulated enzymes expressed in macrophage-rich areas of human atherosclerotic plaques. Atherosclerosis. 2008;196(2):514-522.

124. Moriguchi-Goto S, Yamashita A, Tamura N, et al. ADAMTS-13 attenuates thrombus formation on type I collagen surface and disrupted plaques under flow conditions. Atherosclerosis. 2009;203(2):409-416.

125. Liu CJ. The role of ADAMTS-7 and ADAMTS-12 in the pathogenesis of arthritis. Nat Clin Pract Rheumatol. 2009;5(1):38-45.

126. Burrage PS, Mix KS, Brinckerhoff CE. Matrix metalloproteinases: role in arthritis. Front Biosci. 2006;11(1):529-543.

127. Murphy G, Nagase H. Reappraising metalloproteinases in rheumatoid arthritis and osteoarthritis: destruction or repair? Nat Clin. Pract Rheumatol. 2008;4(2):128-135.

128. Rowan AD, Litherland GJ, Hui W, Milner JM. Metalloproteases as potential therapeutic targets in arthritis treatment. Expert Opin Ther Targets. 2008;12(1):1-18.

129. Voros G, Maquoi E, Collen D, Lijnen HR. Differential expression of plasminogen activator inhibitor-1, tumor necrosis factor-alpha, TNFalpha converting enzyme and ADAMTS family members in murine fat territories. Biochim Biophys Acta. 2003;1625(1):36-42.

130. Yun HJ, Yoo WH, Han MK, Lee YR, Kim JS, Lee SI. Epigallocatechin -3-gallate suppresses TNF-alpha-induced production of MMP-1 and -3 in rheumatoid arthritis synovial fibroblasts. Rheumatol Int. 2008;29(1):23-29. 
131. Luan Y, Kong L, Howell DR, et al. Inhibition of ADAMTS-7 and ADAMTS-12 degradation of cartilage oligomeric matrix protein by alpha-2-macroglobulin. Osteoarthr Cartil. 2008;6(11): 1413-1420.

132. Newby AC, Zaltsman AB. Molecular mechanisms in intimal hyperplasia. J Pathol. 2000;190(3):300-309.

133. Rudijanto A. The role of vascular smooth muscle cells on the pathogenesis of atherosclerosis. Acta Med Indone. 2007;39(2):86-93.

134. Sakoda K, Yamamoto M, Negishi Y, Liao JK, Node K, Izumi Y. Simvastatin decreases IL-6 and IL-8 production in epithelial cells. J Dent Res. 2006;85(6):520-523.

135. Pandian A, Arora A, Sperling LS, Khan BV. Targeting multiple dyslipidemias with fixed combinations - focus on extended release niacin and simvastatin. Vasc Health Risk Manag. 2008;4(5):1001-1009.

136. Sundararaj KP, Samuvel DJ, Li Y, et al. Simvastatin suppresses LPSinduced MMP-1 expression in U 937 mononuclear cells by inhibiting protein isoprenylation-mediated ERK activation. J Leukocyte Biol. 2008;84(4):1120-1129.
137. Vaziri H, Naberhojjati-Roodsari R, Tahsili-Fahdan N, et al. Effect of simvastatin administration on periodontitis-associated bone loss in ovariectomised rats. J Periodontol. 2007;78(8):1561-1567.

138. Morris MS, LeeY, Lavin MT, et al. Injectable simvastatin in periodontal defects and alveolar ridges: pilot studies. J Periodontol. 2008;79(8): $1465-1473$.

139. Seto H, Ohba H, Tokunaga K, Hama H, Horibe M, Nagata T. Topical administration of simvastatin recovers alveolar bone loss in rats. J Periodont Res. 2008;43(3):261-267.

140. Lindy O, Suomalainen K, Mäkelä M, Lindy S. Statin use is associated with fewer periodontal lesions: A retrospective study. BMC Oral Health. 2008;8:16-22.

141. Davignon J. Beneficial cardiovascular pleiotropic effects of statins. Circulation. 2004;109(23 Suppl 1):39-43.

142. Liao JK, Laufs U. Pleiotropic effects of statins. Ann Rev Pharmacol Toxicol. 2005;45:89-118.

143. Ott C, Schmieder RE. The role of statins in the treatment of the metabolic syndrome. Curr Hypertens Rep. 2009;11(2):143-149.
Open Access Rheumatology Research and Reviews

\section{Publish your work in this journal}

Open Access Rheumatology Research and Reviews is an international, peer-reviewed, open access journal, publishing all aspects of clinical and experimental rheumatology in the clinic and laboratory including the following topics: Pathology, pathophysiology of rheumatological diseases; Investigation, treatment and management of rheumatological

\section{Dovepress}

diseases; Clinical trials and novel pharmacological approaches for the treatment of rheumatological disorders. The manuscript management system is completely online and includes a very quick and fair peerreview system, which is all easy to use. Visit http://www.dovepress.com/ testimonials.php to read real quotes from published authors. 